\title{
CURADORIA DE CARNAVAL? PERFORMANCE NA ARTE CARIBENHA CONTEMPORÂNEA E 0 PARADOXO DA ARTE DA PERFORMANCE NA ARTE CONTEMPORÂNEA
}

Claire Tancons

Tradução: Felipe Ferreira

$O$ artigo apresenta esforços presentes e passados para pensar o carnaval como objeto artístico e curatorial, dialoga com discursos atuais que apoiam esses esforços e oferece a contribuição particular da autora, como acadêmica e curadora, para o debate e a prática do carnaval. Embora aborde o carnaval no Caribe e suas diásporas europeia e americana, com foco no modelo do carnaval de Trinidad (o mas') e no legado do trabalho de Peter Minshall e no conceito de roadwork (obra de rua) de Christopher Cozier, trata, em última instância, das preocupações gerais sobre a construção da chamada arte performática como conceito eurocêntrico no contexto da arte contemporânea geral e caribenha especificamente, ambas de predomínio visual, falhando em reconhecer a potência e a circulação do carnaval e outras práticas performáticas vernaculares como formas de arte. Coloca ainda a curadoria em discussão e advoga em favor de uma abordagem experimental relativamente ao objeto do carnaval com as procissões como meio curatorial alternativo.

\section{ARTECARIBENHACONTEMPORÂNEA, PERFORMANCE, EUROCENTRISMO, ROADWORK, ARTE, CARNAVAL, MAS', TRINIDAD, PROCISSÃO}

TANCONS, Claire. Curadoria de carnaval?: performance na arte caribenha contemporânea e o paradoxo da arte da performance na arte contemporânea. Textos escolhidos de cultura e arte populares, Rio de Janeiro, v.8, n.2, p. 23-40, nov. 2011. 
Desde 1969, as celebrações do carnaval caribenho no dia 1ํ de setembro têm transformado as regras dos dias de trabalho em desfiles de lazer na principal avenida do Brooklyn, Nova York, a Eastern Parkway. Saída dos salões de baile da Renascença do Harlem para as ruas do antigo bairro New Negro (outra designação do Harlen) e migrando para os Crown Heights após o Movimento pelos Direitos Civis (Civil Rights Movement) em torno de 1963, a história do carnaval foi tão complexa nos Estados Unidos quanto no Caribe, assim como sua localização dentro das artes, igualmente complexa em ambos os lugares, como se vê, por exemplo, na relação entre a parada do American Day, nas Índias Ocidentais, como é atualmente conhecida, e o Brooklyn Museum of Art, ao qual ela teve

1. Este ensaio foi encomendado por David Bailey, Alissandra Cummings, Axel Lappe Allison Thompson para o livro Curating in the Caribbean (The Green Box, Berlin, 2011) do qual são editores. Título original: Curating Carnival?: performance in Contemporary Caribbean Art and the Paradox of performance Art in Contemporary Art.

2. Sobre o tema, ver Nunley and Bettelheim (1988). A exposição foi aberta no St Louis Art Museum em 1988. Embora os organizadores da exposição e os autores do catálogo possam discordar da caracterização de sua abordagem como folclóri$\mathrm{ca}$, afirmações como "Os elementos [do festival], assim como as pessoas, são diferentes, embora juntos criem uma estética pan-caribenha doce $e$ pungente", presente na orelha do catálogo, transforma-a em algo exótico e traduz um tipo de essencialismo difundido por visões eurocêntricas de culturas não europeias. acesso garantido, embora limitado, durante as quatro décadas passadas em sua porta. ${ }^{1}$

O carnaval teve chegada marcante no Brooklyn Museum dos anos 90 com a exibição do Caribbean Festival Arts, organizado por John Nunley e Judith Bettelheim. Os discursos e mostras dessa exibição eram, entretanto, bastante antropológicos, apresentando o carnaval e as festas de Hosay e Junkanoo como emanações folclóricas de culturas diaspóricas históricas em vez de manifestações artísticas vibrantes de redes globais contemporâneas. ${ }^{2} \mathrm{O}$ carnaval teve também promissora apresentação no Brooklyn Museum em 1999, sob a forma de palestra intitulada Minshall e o Mas' e de performance - The Dance of the Cloth - apresentada por lendário artista de Trinidad, Peter Minshall, fabuloso batalhador pelo reconhecimento do status artístico do carnaval.

Quase dez anos depois, a exposição Infinite Island: Contemporary Caribbean Art organizada por Tumelo Mosaka para o Brooklyn Museum, embora dedicada a "Carlos Lezama (19232007), fundador da parada e do dia de carnaval americano das índias ocidentais do Brooklyn, um campeão da cultura caribenha", deixou o carnaval do lado de fora mais uma vez. A advertência de Annie Paul (2007, p. 32) no ensaio que escreveu para o catálogo da mostra não foi considerada. "A arte visual caribenha não se pode basear em conceitos e argumentos modernistas estreitos sob pena de arriscar sua extinção", ela registrou, lamentando a moldura ocidental reducionista em que a arte caribenha estaria confinada. Com base nas noções de moderno, de vernacular e de cosmopolita articuladas por Homi K. Bhabha (1996) dentro do conceito de "cosmopolitismo vernacular" e por Kobena Mercer (2008) no conceito de "modernismo cosmopolita", a crítica de cultura baseada na cidade de Kingston considera o baile jamaicano (Jamaican Dancehall) "representando um moderno 
vernacular ou cosmopolitismo vernacular em oposição fundamental ao alto modernismo de um mundo da arte delicadamente construído" (p. 30). Ela poderia ter falado nesses mesmos termos igualmente bem do carnaval de Trinidad, outro moderno vernacular.

Pode-se discutir se o carnaval, para não falar dos bailes jamaicanos, deve ou não entrar no museu. A questão se coloca constantemente, mesmo que de forma ambígua, na maior parte das exposições de arte caribenha organizada nos Estados Unidos nas últimas duas décadas. O principal desafio que essa questão buscou enfrentar foi a validação artística do carnaval, tarefa tradicionalmente atribuída a esse grande porta-estandarte artístico, o museu. A outra questão, mais fundamental, sobre se o carnaval deve sofrer curadoria e, em caso positivo, se ele deve ou pode ter curadoria externa ao contexto do museu ou de espaços de exibição, continua sem resposta.

Inspirando-se na noção de modernismo vernacular como possível forma de escapar das ideias estabelecidas referentes a valor artístico e princípios curatoriais, artistas e curadores ainda precisam articular questões e fazer proposições que escapem da visão dicotômica que estabelece o que pode sofrer curadoria e o que não pode, o que pertence e o que não pertence ao museu.

O presente artigo apresenta esforços passados e presentes realizados para apontar o carnaval como um objeto artístico e curatorial, discute discursos contemporâneos que apoiam esses esforços e oferece as contribuições da autora para o debate e a prática do carnaval. Faz isso como parte dos discursos e práticas da arte caribenha contemporânea assim como da performance dentro da arte contemporânea.

\section{PARTE 1}

Em geral o carnaval tem sido, na melhor das hipóteses, marginalizado ou, na pior, deixado totalmente de fora das exibições de arte caribenha contemporânea nos Estados Unidos e na Inglaterra, onde a maioria dessas mostras tem sido organizada. Ele está virtualmente ausente de todas as exibições de arte contemporânea não caribenhas assim como de todas as exibições de arte no Caribe. A seguir, alguns exemplos de duas décadas de exibições de arte contemporânea caribenha nos Estados Unidos e Inglaterra. Um exercício similar poderia ser feito com relação ao carnaval no Brasil, mas, neste ensaio, restringirei meu argumento ao carnaval no Caribe. Como se verá, o carnaval de Trinidad, o mais famoso e sob certos aspectos o mais avançado artisticamente do Caribe, é também o mais representado.

Caribbean Visions: Contemporary Painting and Sculpture (1995) - organizada por Art Services International para alguns museus americanos, incluindo o Center for Fine Arts em Miami e o New Orleans Museum of Art - já em seu título indica claramente seu foco nas mídias tradicionais da pintura e escultura e não aborda o carnaval. Entretanto, e de certo modo paradoxalmente, o catálogo incluiu dois ensaios celebrando a importância do carnaval na arte e na cultura do Caribe: Trinidad Carnival: history and meaning de Errol Hill (1995), o grande professor de drama e oratória no Dartmouth College e autor de The Trinidad Carnival: Mandate for a National Theatre (1972) - e Carnival and its place in 
Caribbean culture and art (MINSHALL, 1995) - escrito pelo aclamado designer do carnaval contemporâneo de Trinidad e autointitulado masman.

Por outro lado, na exposição Caribe Insular. Exclusión, Fragmentación, Paraíso, organizada por Antonio Zaya para a Casa de América em Madri, em 1998, a banda carnavalesca de Peter Minshall no mesmo ano, RED, não só figurava na capa do catálogo como tinha sido incluída na exibição. O catálogo também apresentava vários trabalhos sobre o carnaval em Trinidad: um texto de artista, por Peter Minshall, um texto sobre a RED, da Callaloo Company, empresa de produção carnavalescas de Minshall, e um ensaio do curador, crítico de arte e artista de Trinidad, Christopher Cozier (1998a), no qual uma das seções Roadworks' Searching for a Starting Point?, era dedicada à importância e relevância do carnaval para a cultura contemporânea do Caribe.

Significativamente, Rockstone and Bootheel: Contemporary West Indian Art (2010) - uma exposição em Hartford, Connecticut, focada em obras das Bahamas, Barbados, Jamaica e Trinidad e Tobago, países caribenhos de língua inglesa, com curadoria de Kristina Newman-Scott e Yona Backer para a Real Art Ways - era acompanhada por duas exibições abordando as tradições de performance caribenha, uma, intitulada Trinidad Carnival, com os Blue Devils de Zak Ové, e a outra, Jamaican Dancehall, com apresentação de posters por Maxine Walters. De fato, o próprio título da exposição, Rockstone and Bootheel, foi emprestado de uma canção jamaicana de autoria de Gibby. Entretanto, ambas as exposições, a primeira de fotografias de carnaval e a última de posters de bailes, mantinham o traço performativo dentro dos limites da representação e não da apresentação. That is Mas, incisivo ensaio do crítico literário Nicholas Laughlin, foi a maior contribuição dessa exposição para a compreensão da importância do carnaval "como um recurso para nossos artistas que representam a si mesmos no palco mundial" (LAUGHLIN, 2010, p. 22-27). ${ }^{3}$ A exposição do próprio Cozier, Wrestling with

3. Por "nossos artistas" Laughlin se refere àqueles de Trinidad e possivelmente do Caribe. Laughlin também cita uma passagem do ensaio The Greatest Free Show on Earth. Carnival from Trinidad to Brazil, Cape Town to New Orleans (TANCONS, 2008). the Image: Caribbean Interventions, no Art Museum of the Americas em Washington (2011), da qual ele foi cocurador, lidava com a performance de modo bastante similar à abordagem que Rockstone and Bootheel fazia das representações performáticas nos trabalhos de artistas como Ebony Patterson e Marlon Griffith. O tempo dirá como será a abordagem da planejada seção de carnaval na futura exposição pan-caribenha Caribbean: Crossroads of the World (2012), organizada em conjunto pelo The Queens Museum of Art, The Studio Museum in Harlem e El Museo del Barrio.

Na Inglaterra, mesmo a corrente de reavaliação das práticas da arte moderna dentro do contexto expandido do Black Atlantic não teve sucesso em recentralizar o carnaval, afastando-o das margens às quais ele tem sido relegado. $\mathrm{Na}$ exposição Afro Modern: Journeys through the Black Atlantic (Tate Liverpool, 2010), o carnaval aparecia apenas como nota de rodapé na grande narrativa da mostra, através da projeção do filme seminal Orfeu Negro (1959), rodado durante o carnaval do Rio de Ja- 
neiro. Em 2000, a Hayward Gallery montou a exposição Carnivalesque, largamente baseada na teoria do mesmo nome de Mikhail Bakhtin, para celebrar importante movimento na vida cultural da Inglaterra e da Europa. Lançando o olhar para além de Bakhtin e das tradições carnavalescas europeias e seu próprio carnaval diaspórico pós-colonial, duas exposições foram organizadas sobre o carnaval de Notting Hill (Londres), sem dúvida resultados do reconhecimento do evento carnavalesco londrino arduamente conquistado após lamentáveis protestos: uma, Masquerading: The Art of the Notting Hill Carnival, organizada pelo Arts Council of England em 1986, no auge dos discursos multiculturais, e, mais recentemente, Midnight Robbers. The Artists of Notting Hill Carnival, em 2007, no London City Hall e, posteriormente, em galerias de arte de universidades americanas (Ohio State University e University of Memphis).

A afirmativa de que o carnaval é centralmente marginal não é menos paradoxal do que a ideia de uma exibição de pintura e escultura devotando dois ensaios ao carnaval ou de outra dedicada à memória do fundador do carnaval que ostensivamente o exclui de seu contexto. Talvez sensatamente os curadores dessas exposições tenham percebido a inadequação do carnaval ao formato das mostras e ao enquadramento em museus. A escassez de textos críticos sobre carnaval sugere, na verdade, que o carnaval não está dentro do horizonte do artístico e do curatorial. Nas vezes em que esteve, foi colocado dentro das tradições antropológicas e representacionais, por meio de apresentações de objetos ou fotografias e não das próprias ações performáticas. Então, que oportunidade mais propícia poderia haver para se avançar no debate sobre o lugar não só do carnaval, mas da performance em geral dentro das práticas da arte caribenha contemporânea do que o momento em que a dita arte performática domina os principais discursos da arte contemporânea?

Nos Estados Unidos, o discurso sobre a arte performática é dominado basicamente pelos termos estabelecidos pela curadora e historiadora da arte RoseLee Goldberg. Na qualidade de um constructo teórico que emergiu no final dos anos 70 eles seguem de perto sua narrativa consagrada em Performance: Live Art, 1909 to the Present (1979), considerada por alguns "a bíblia", e em Performance: Live Art since the 60 s (1998). ${ }^{4}$ Como campo de prática curatorial as artes performáticas encontraram sua maior representação na bienal Performa, desde 2005 a bienal nova-yorkina da "nova arte performática visual" organizada pela Performa, organização sem fins lucrativos de Goldberg que "se compromete com a pesquisa, desenvolvimento e apresentação da performance por artistas visuais de todo o mundo". ${ }^{5}$ Enquanto a narrativa da arte performática se apresenta principalmente na América do Norte, Europa e Japão, suas representações canônicas são mostradas dentro dos cubos brancos de galerias e nas caixas pretas de teatros, ambos não apropriados para exibir práticas artísticas urbanas baseadas

4. Performance: Live Art 1909 to the present foi editado primeiramente por Abrams em 1979, reeditado por Thames and Hudson, em 1988, revisado, ampliado e reeditado pela mesma editora em 2001 como Performance Art: from futurism to the present. Performance: Live Art since the 60s foi publicado, também pela Thames and Hudson, em 1998 e 2004.

5. www.performa-arts. org (10 jul. 2011). 
6. Inspirado por sua experiência no carnaval da Bahia, onde geralmente se apresenta sobre um trio elétrico, Lindsay, um músico da geração Tropicália e participante da estridente vanguarda em Nova York, tem organizado desfiles em colaboração com artistas como Matthew Barney e Rikrit Tiravanija no Brasil, Europa e Estados Unidos desde 2004. nas ruas, tal como o carnaval. Uma exceção notável foi Something I Heard, de Arto Lindsay, para Performa 09, uma procissão inspirado por sua experiência no carnaval da Bahia, que teve lugar na Times Square à noite. ${ }^{6}$

O posicionamento da arte performática nos cânones da corrente dominante euro-americana, faz-me propor a seguinte pergunta: será a performance o último bastião do eurocentrismo no discurso e prática da arte contemporânea? Ou, em outras palavras, será a arte performática um conceito eurocêntrico? Poderia o carnaval só encontrar seu caminho no espaço sagrado da arte performática através da esperta desconstrução da forma de Lindsay? E especificamente no que se refere à arte caribenha contemporânea: que importância tem, na verdade, terminologias como "arte performática visual" ou simplesmente "arte

performática" para a arte caribenha contemporânea? Pode a arte caribenha oferecer plataforma para se iniciar uma investigação sobre a diferença epistemológica entre as artes performáticas e a arte da performance?

\section{PARTE 2}

A quase total ausência do carnaval das exposições de arte caribenha concorda com seu quase apagamento nos manuais de história da arte caribenha contemporânea. Como exemplo, Caribbean Art, de Veerle Poupeye (1998) não dedica nenhum capítulo, por menor que seja, ao carnaval. Existem dezenas de livros sobre vários carnavais caribenhos, a maioria sobre o de Trinidad, seguindo-se o da Guiana Francesa. Para a maioria das festas carnavalescas da região, entretanto, seus carnavais ainda precisam de relatos históricos apropriados. Frequentemente, quando consideramos as publicações acadêmicas, as principais disciplinas a abordar os carnavais são a antropologia e a história, raramente a história da arte ou mesmo os estudos visuais. Uma exceção é Carnival: Culture in Action - The Trinidad Experience, editado por Milla Riggio (2004), com prefácio de Richard Schechner, fundador e chefe do departamento de estudos da performance na NYU, que introduziu o carnaval no campo acadêmico criado por ele e combina abordagens das disciplinas mencionadas com outras mais.

Nos anos 70, após a independência das colônias inglesas no Caribe, práticas performáticas de artistas caribenhos foram discutidas por acadêmicos tais como o trinitário Errol Hill (1921-2003) e o jamaicano Rex Nettleford (1933-2010) - vice-chanceler emérito da University of the West Indies (UWI), além de coreógrafo e fundador da National Dance Theater Company of Jamaica - dentro do contexto das artes performáticas, principalmente teatro para o primeiro e dança para o último, em meio aos nascentes discursos nacionais. Carnaval, segundo Hill, seria o Teatro Nacional de Trinidad, e para Nettleford a Jamaica deveria ter uma Companhia Teatral Nacional de Dança. O caminho para o reconhecimento de formas vernaculares de expressão, artística ou outras, era através da 
legitimação acadêmica dentro de disciplinas ocidentais. O exercício frequentemente implicava a inclusão de conteúdo vernacular em formas ocidentais padronizadas, ou a utilização de formas vernaculares para interpretar música pop clássica europeia ou americana, como ainda se dá na steel band, instrumento musical vernacular de Trinidad. Sem dúvida isso foi considerado um avanço comparado à simples não integração do vernacular nos repertórios de teatro, dança ou música, como teria sido o caso durante o período colonial.

Passando para os anos 90 e voltando ao carnaval. A partir de meados da década de 1990, Peter Minshall, juntamente com Todd Gulick, gerente de produção da Callaloo Company, começou a substituir o discurso sobre o carnaval ligado ao campo das artes cênicas pelo das artes visuais, embora Minshall tivesse vindo do teatro, tendo estudado design teatral na Central St Martins School of Art and Design em Londres, em meados dos anos $60 .{ }^{7}$ Minshall e Gulick, especificamente, orientaram o carnaval em direção à arte performática, auxiliados pelo conceito de mas' que eles ajudaram a formar. Mas', abreviatura de masquerade, é o termo popular para carnaval em Trinidad e em outros países caribenhos de língua inglesa, nos quais, participar do carnaval é "brincar o mas"'8, equivalente a "rush", no Junkanoo ou "courrir le vidé", em Guadalupe e na Martinica. A palavra mas' certamente

7. Entre muitos projetos teatrais, Minshall criou os cenários para Man Better Man, de Hill, no Dartmouth College, em 1975.

8. To play mas' (N.T.). não foi inventada por Minshall, mas ele se apropriou dela para se referir à forma carnavalesca "mais visual" e, por extensão, a seu próprio trabalho, definindo ou ajudando a definir mas' como um gênero artístico. A palestra de Minshall em 1999 no Brooklyn Museum foi intitulada Minshall e o Mas' e ele se orgulha de se denominar um masman, alcunha presente no título de recente documentário sobre seu trabaIho (Masman Peter Minshall, por Dalton Narine, 2010). Em Carnival and its Place in Caribbean Culture and Art, ensaio escrito para a revista Caribbean Visions, ele afirma:

Para se avaliar o lugar do carnaval na cultura e arte do Caribe é necessário perceber que o carnaval incorpora ampla variedade de formas e atividades. Carnaval em Trinidad inclui: músicas cantadas (calipso e soca), música instrumental (steel bands e orquestras de metais) e desfiles à fantasia junto com a dança e os movimentos através dos quais eles se apresentam (mas') (...) A mais visual das formas é o que chamamos de mas': a tradição das mascaradas no carnaval de Trinidad (MINSHALL, 1995, p. 50) (grifo meu).

E segue afirmando, referindo-se especificamente ao mas' como "uma arte performática", "performance" ou "arte performática":

Mas' é arte performática. Não é meramente visual; uma fantasia de mas' apresentada num manequim não é mas' (...) Embora seja performance, mas' não se enquadra no molde de nenhuma das artes performáticas mais convencionais. É teatral, mas é necessariamente mais amplo em seu alcance, mais simbólico, mais simples do que o teatro narrativo convencional. Envolve dança, mas essa dança é frequentemente mais espontânea do que coreografada; ou seja, é dança que objetiva articular mais o mas' que é vestido do que o corpo que o está vestindo. Está mais ligado àquilo que se tornou conhecido como 
simples "performance" ou "arte performática", porém o mas' apresentou essas características inocente e inconscientemente, muito antes de a expressão "arte performática" ter sido criada (p. 51).

"Muito do que foi dito sobre 'performance' como disciplina de vanguarda aplicase igualmente ao mas"', escreve Minshall (1995, p. 56-57) que, em nota de rodapé, cita diretamente trecho de Performance: Live Art to the Present, de RoseLee Goldberg:

performance tem sido um modo de apelar diretamente para um grande público assim como chocar audiências fazendo-os reavaliarem suas próprias noções de arte e sua relação com a cultura...

[Por] sua própria natureza, a performance desafia definições precisas ou fáceis para além da simples declaração de ser arte ao vivo feita por artistas... Pois a performance se baseia livremente em um número de referências - literatura, teatro, drama, música, arquitetura, poesia, filme e fantasia - desdobrando-as em qualquer combinação.

Nenhuma outra forma artística de expressão pode definir-se como tendo manifesto tão sem limites... Os manifestos acompanhando muitos desses trabaIhos estabelecem uma moldura e uma visão utópica para uma arte totalmente inclusiva que nenhuma pintura, escultura ou monumento arquitetônico pode esperar alcançar por si mesmo (p. 56-57).

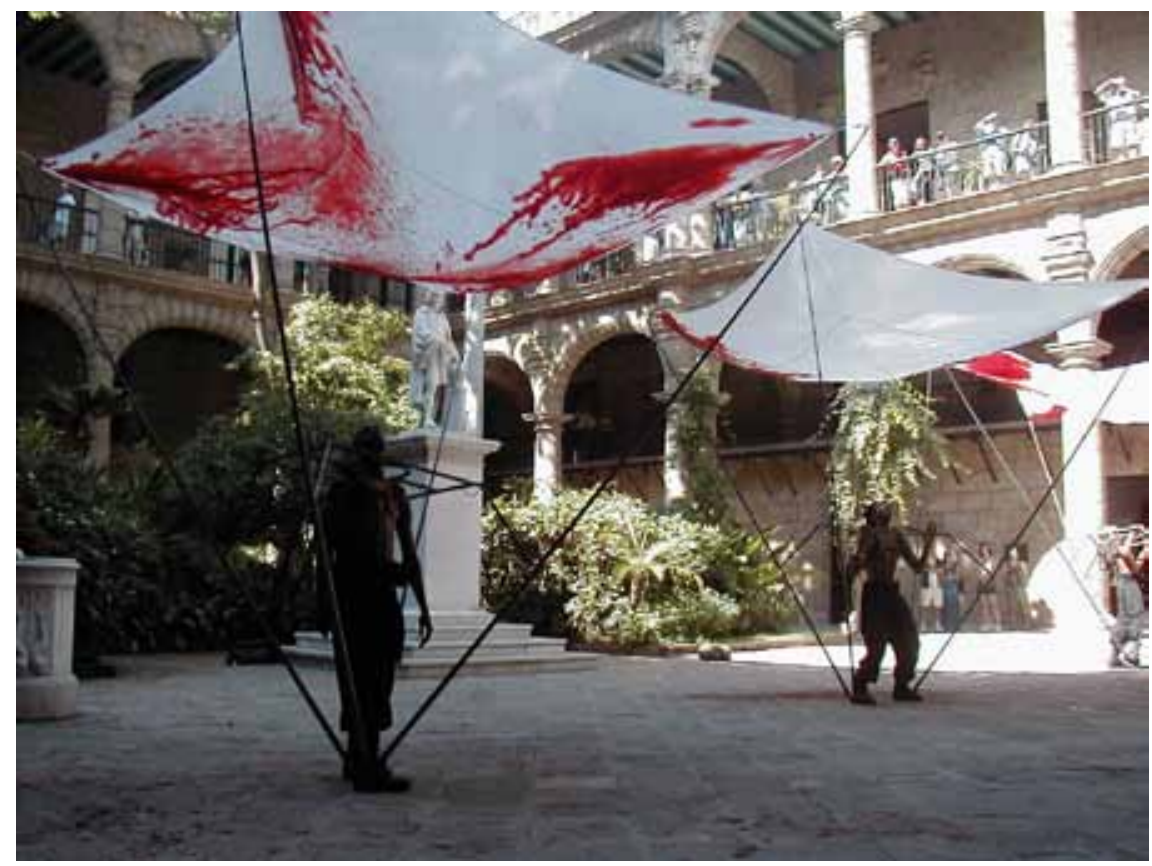

Figura 1: Peter Minshall, The Dance of the Cloth (apresentada por membros da Callaloo Company), Havana, Palácio Municipal, VII Bienal de Havana, 2000 Foto: Charlotte Elias. Cortesia de Callaloo Company, Chaguaramas, Trinidad. 
Minshall, entretanto, reconhece que a arte performática e o mas' não são totalmente idênticos e que existem muitos modos nos quais o mas' não é arte performática. No mesmo ensaio ele afirma:

O campo da arte "performática" tem sido descrito como uma pesquisa natural em resposta à crescente irrelevância da arte convencional orientada para o objeto com relação ao mundo moderno. $\mathrm{O}$ mas' pode oferecer igual oportunidade de transcender o objeto em favor da experiência de um modo não elitista nem inacessível, mas através de sua natureza popular e participatória (p. 50).

Eu acrescentaria que a arte performática certamente não é mas' e que outra grande diferença entre o mas' e a arte performática, além do fato de ele ser popular e participatório, é ser também coletivo em escola massiva de uma forma que poucas performances artística são.

Dez anos depois, o artista e crítico de arte Luis Camnitzer retoma o argumento sobre o mas' como arte performática em The Keeper of the Lens, seu ensaio para Looking at the Spirits: Peter Minshall's Carnival drawings (2005), exposição no Drawing Center cuja curadoria ele dividiu com Gulick:

Carnaval em Trinidad, ou mais precisamente mas' - uma derivação de masquerade usada como em "brincar o mas' - apresenta praticamente todas as dinâmicas da arte performática e instalações mais ousadas, antecipando essas formas em mais de um século (CAMNITZER, 2005, p. 5)

$\mathrm{O}$ argumento foi também usado por comentadores de arte dispersos, como William Dunlap, que escreveu, num "especial para o Washington Post", sobre The Dance of the Cloth (Figura 1), uma adaptação de Minshall para Mancrab - o rei de uma das bandas em sua trilogia de bandas intitulada River - para a VII Bienal de Havana (2000):

Qualquer obra de arte performática terá grande dificuldade de competir com os músicos das ruas de Havana, com as senõritas fantasiadas, com malabaristas, engolidores de fogo, equilibristas sobre barris de Obispo e leitores de cartas de tarô fumando charutos (...) Uma obra, entretanto foi triunfante e fez com que toda a viagem valesse a pena (DUNLAP, 2001, p. G4).

The Dance of the Cloth, entretanto, poderia pertencer legitimamente à arte performática, ou, na verdade, à versão mais próxima do mas' enquanto arte performática, visto que consistia numa retomada do Mancrab (homem-caranguejo), principal disfarce da masband River, em performance realizada no pátio do Palácio Municipal. Ela foi definida por Gulick (s/d) da seguinte forma: "Fora do contexto do carnaval, esse tipo de performance pode ser chamada de teatro-mas', uma forma de arte performática."

Assim como Minshall e Gulick haviam feito, Camnitzer (2005, p. 5) também usou alguns dos argumentos sobre a falta de reconhecimento do carnaval no mundo da arte dominante: "Por pertencer a uma história diferente, ele é considerado expressão popular local e vernacular, sem significância para qualquer especulação sobre a 'grande arte'".

Minshall e Camnitzer, assim como Cozier e Dunlap, concordam: se o mas' tivesse que ser produzido fora de Trinidad, nos centros sempre mutáveis da arte contemporânea dominante, ele criaria rebuliço sem precedentes. Cozier (1998a, p. 349) afirma: 
Se algo como isso fosse acontecer em um dos alegados lugares de poder da teoria da arte, haveria milhares de textos sobre o tema. Até agora ele é percebido como um simples festival de rua, ou folclórico, sujeito a interpretações culturais de artistas locais e estudos de caso antropológicos estrangeiros.

Entretanto, a maior contribuição de Cozier ao debate sobre o lugar do carnaval no discurso da arte contemporânea, e sobre o carnaval como forma de arte, reside em sua habilidade em definir o mas' citado por Minshall como "estratégias de arte visual e teatral contemporânea para dar novo formato e significado às caracterizações folclóricas e ao carnaval tradicional" e usar as noções de momentos e monumentos, ecoando o conceito de lieu de mémoire, ou lugar de memória, de Pierre Nora, para definir o mas. Em texto intitulado "Mancrab", Cozier (s/d, p. 2) afirma:

Através de sua obra, Minshall sempre propõe uma compreensão crítica alternativa do "monumental" em oposição ao que é afirmado em livros de história da arte convencional. Ele nos incita a repensar o vernacular e o efêmero; a considerar os modos como as ações ou "um momento" podem também viver através de memória e discurso (grifos meus).

E em seu ensaio para o catálogo Caribe Insular:

Com exceção dos fenômenos geológicos, não há monumentos nas ilhas do Caribe tais como pirâmides, catedrais ou torres, mas temos nosso povo; suas histórias pessoais são definidas por sua língua, seus gestos e sua visão (COZIER, 1998a, p. 348).

Pode-se argumentar que existem monumentos no Caribe, nas Grandes Antilhas mais do que nas Pequenas Antilhas, e que o carnaval não é menos vibrante no Brasil, cuja arquitetura, que vai do barroco ao moderno, dá sentido à própria noção de monumental (para não citar o sambódromo de Oscar Niemeyer no Rio de Janeiro). O objetivo de Cozier com essa afirmação é menos sugerir que há relação direta entre a ausência de monumentos e a existência do carnaval e mais o de criar um vocabulário crítico dentro das especificidades do vernacular mantendo-se, ao mesmo tempo, atento ao contexto da arte global. Em versões anteriores desse ensaio, Cozier propõe o termo roadwork (obra de rua) para se referir ao trabalho de Peter Minshall: "Visto que muitas das atividades em

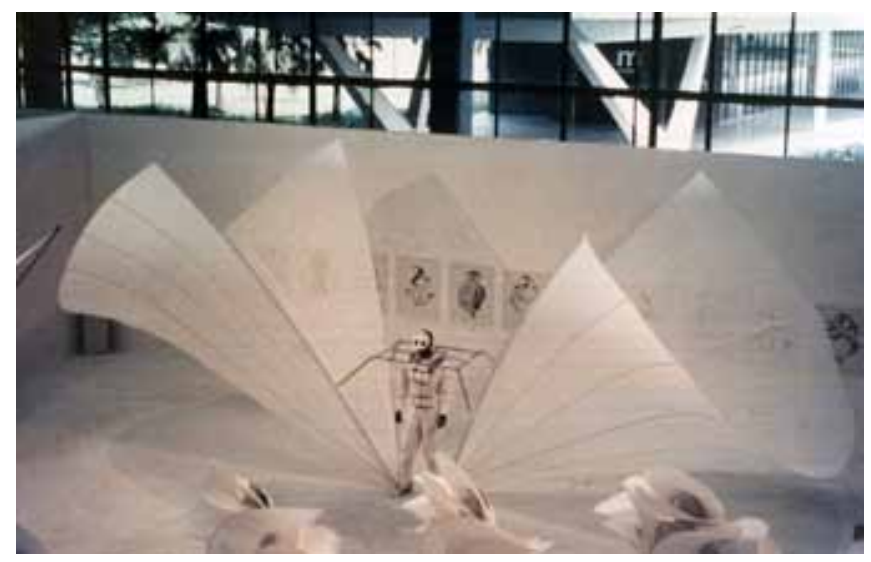

Figura 2: Peter Minshall, Peter Minshall: Callaloo, an Exhibition of Works from the Carnival of Trinidad, XIX Bienal de São Paulo, 1987 Foto: Todd Gulick. Cortesia de Callaloo Company, Chaguaramas, Trinidad. 
torno de nossas vidas são atividades de rua penso que é interessante substituir a palavra arte pela palavra rua (road)" (COZIER, 1998b, p. 2). Na versão publicada em Caribe Insular ele escreveu: "O trabalho de arte, ou o roadwork [de Peter Minshall], como gostaria de chamá-lo, visto que ele se apresenta em performaces na rua (...)" (COZIER, 1998a, p. 348)

Como poderia a virada epistemológica operada por Cozier, de obra de arte para obra de rua, afetar a forma como o carnaval é concebido e, por extensão, como é abordado curatorialmente?

\section{PARTE 3}

Deve-se notar que três dos mais influentes críticos e teóricos do carnaval, Camnitzer e, principalmente, Minshall e Cozier, são artistas. Desse modo, dois artistas atuantes no carnaval, Minshall e Marlon Griffith, sobretudo o primeiro, são os que mais avançaram na questão da curadoria do carnaval. Vale a pena também mencionar que tanto Minshall (nascido em 1941) quanto Griffith (nascido em 1976) receberam bolsas do Guggenheim, o primeiro em 1982, em design e cinética de carnaval, e o segundo em 2010, em belas artes, fatos que, juntamente com a especificidade das práticas dos artistas, podem indicar a apreciação - ou cooptação - crescente do carnaval o espaço das artes visuais.

De meados dos anos 80 até 2000, o trabalho de Minshall foi repetidamente apresentado em instituições de arte britânicas e duas vezes em bienais internacionais de arte. ${ }^{9}$ Em cada um desses eventos o papel de Minshall era proeminente na escolha das obras e em sua forma de apresentação. De acordo com Gulick, que escreveu muitos dos textos dos catálogos, Minshall

confrontava-se com a dificuldade de tentar apresentar uma obra de arte performativa dinâmica em um espaço estático de galeria e, em resposta a isto, selecionava um trabalho cuja forma da fantasia mas' era especialmente escultórica ou mesmo estática (...) incluindo vídeo e som. ${ }^{10}$

Essa afirmação - que se aplicava à opção de Minshall pela masband Callaloo (1984) em seu primeiro convite para apresentar seu trabalho em exposição, intitulada Callaloo by Minshall, em galerias de arte, a Arnolfini, em Bristol, e a Riverside Studios, em Londres (1986), exposição mais tarde remontada na XIX Bienal de São Paulo (1987) (Figura 2) - poderia ser feita em relação à masband RED que ele optou por exibir na VII Bienal de Havana (2000) e, mais tarde na já mencionada mostra no Drawing Center. Nos dois casos a escolha de uma só masband para ser exibida reflete o desejo de Minshall de "transmitir a integridade e coerência de única (embora multifacetada) obra de arte" (ver nota 10). Enquanto Callaloo era de fato "especialmente escultórica", RED era particularmente visual, e ambas as masban-

9. Outras exposições de arte dos trabalhos de Minshall no Reino Unido, além das já mencionadas no texto, são: The Dancing Mobile, de obras de mas' de Minshall (Leicestershire Museum \& Art Gallery, Leicester, Inglaterra, 1990) e importante seção com obras de Minshall criadas para o carnaval de Trinidad e para a cerimônia de abertura dos Jogos Olímpicos de Barcelona, em The Power of the Mask (National Museums of Scotland, Edinburgh, Escócia, 1993).

10. Todd Gulick, 24 fev. 2011, e-mail trocado com a autora. 


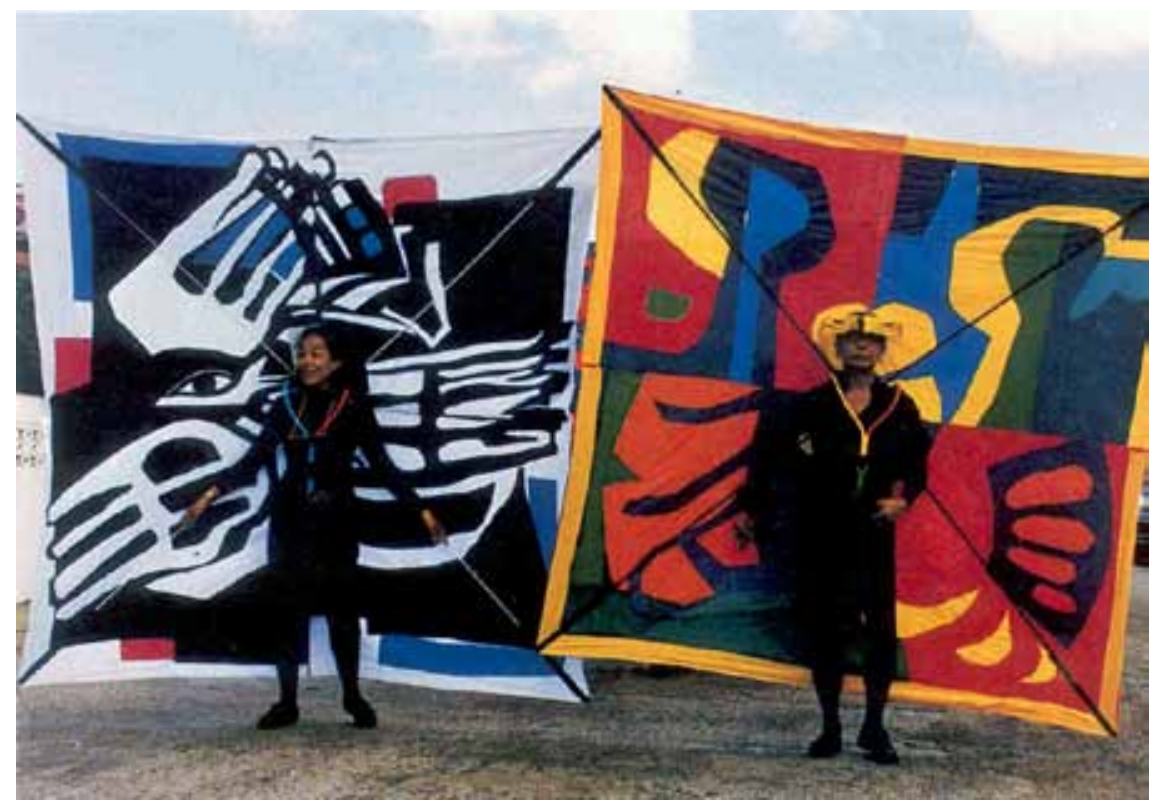

Figura 3: Peter Minshall, Artists Squares em Tantana, Port of Spain, carnaval de Trinidad, 1999; quadrados de artista de Carlysle Chang (à direita), vestido pelo próprio, e de Lisa Henry Choo-Foon (à esquerda), vestida por Carol Aqui Foto: Noel Norton. Cortesia de Callaloo Company, Chaguaramas, Trinidad.

ds ilustram o diálogo contínuo de Minshall com as artes visuais. Entretanto suas exibições em espaços de galerias pareciam bastante tradicionais e mesmo autoritárias - desenhos de fantasias foram pendurados nas paredes e fantasias foram montadas em manequins apesar de características bastante inovadoras para a época: ambientação com sons e vídeos além de detalhes em que se podia notar a mão de Minshall: manequins pintados de preto e sofisticadas apresentações de vídeo em multicanais.

Como experimento curatorial realizado por Minshall em seu próprio meio, o mas' apresentou-se, afinal, como o mais inovador. Se com Carnival is Color (1987) o artista matou dois coelhos com uma só cajadada - levando diversão às mentes estreitas das ilhas, que, ao dizer que o carnaval é cor (carnival is color) entendem que o carnaval deve ser divertido e não sério, e criticando fortemente as pretensões sofisticadas do mundo da arte com seções intituladas Horizontal Primaries (cores primárias horizontais), Tangerine Expanding (expansões tangerina) e Uncomposed Red Lines in Space (linha vermelha incomposta no espaço) -, com Tantana (1990) ele concebia uma seção inteira como "exibição de grupo como evento público de arte, concebido, encomendados e com curadoria feita por [ele mesmo]" (ver nota 10). Tomando como premissa quadrados de tecido aplicado, Minshall convidou cerca de 15 artistas consagrados, entre os quais ao menos um que também era masman, Carlysle Chang, juntamente com Lisa Henry Choo Foon e LeRoy Clarke entre outros, para contribuir com desenhos costurados pela companhia de artesãos Callaloo que, unidos, formavam a seção chamada Quadrados de artista (Figura 3). 
Como Chris Cozier, que não aceitou o convite para participar dos Quadrados de artistas, antecipou, essa "exibição de quadrados de tecidos, ou 'pinturas dançantes'", nas palavras de Minshall, presos às costas dos mascarados como se fossem pipas (cujas varas foram usadas para reforço) sem vento ou velocidade para fazê-las saírem do chão era algo estranho. ${ }^{11}$ Possivelmente ainda mais promissora, e menos presa à mídia sacrossanta da pintura, que Minshall respeitava profundamente apesar de toda sua irreverência contra ela, era outra apresentação da decididamente desenfreada banda Tantana, uma seção para crianças, Bacchacs (palavra vernácula para uma formiga local carregadora de folhas) criada pela artista e maswoman Kathryn Chan que, em lugar de tentar reproduzir suas próprias pinturas sobre uma tela, usou o mas' como mídia.

Mantendo sua preocupação no sentido de legitimar o carnaval ao compará-lo à arte performática, Minshall buscou caminhos para traduzir as masbands em peças de arte performática no contexto da galeria de arte ou da bienal. Se para a instalação Callaloo by Minshall, na galeria Arnolfini em Bristol, Minshall criou uma masband original, Drums and Colours, para acompanhar a exposição, um ano depois, na Bienal de São Paulo, ele apresentou, nos dias que precederam a abertura, uma performance improvisada de The Dance of the Cloth com o acompanhamento de percussão pré-gravado, para plateia de cerca de 100 espectadores. The Dance of the Cloth foi, mais tarde, reprisado em 1999 no Brooklyn Museum como acompanhamento de sua palestra e em 2000 na VII Bienal de Havana. Neste último caso, mais de uma década depois da primeira apresentação, Minshall não era mais o único performer a improvisar, ou mesmo a participar como performer, mas vários membros da Callaloo Company apresentaram performance ensaiada no pátio do Palácio Municipal. Mas, como foi o caso em relação à pintura, dentro do conceito de mas' Minshall não estaria demasiadamente preso ao conceito de arte performática nessa mostras de arte contemporânea às quais, para o bem ou para o mal, ele tentava adaptar-se? Cozier, que viu a performance duas vezes, disse que "ali havia alguma coisa...". ${ }^{12}$ Infelizmente, uma planejada exposição retrospectiva, desenhada por Chan, e uma publicação, editada por Cozier e outros seguidores fiéis, tais como a editora e escritora Patricia Ganase, ambas capazes de garantir a Minshall o reconhecimento do mundo da arte oficial que ele tanto queria, foram abortadas em 2006.

Marlon Griffith, um discípulo de Cozier com o qual aperfeiçoou seu desenho e suas habilidades gráficas mais do que com Minshall, em cujo mascamp ele praticou, parece ter sido direcionado a outro caminho. Quando apresentou seu trabalho no contexto de uma galeria de arte, Griffith relutou boa parte do tempo em apresentar fisicamente, no espaço da galeria, uma masband com manequins, buscando, ao contrário, recriar fenomenologicamente o sentimento de estar imerso numa masband. Em Lighting 


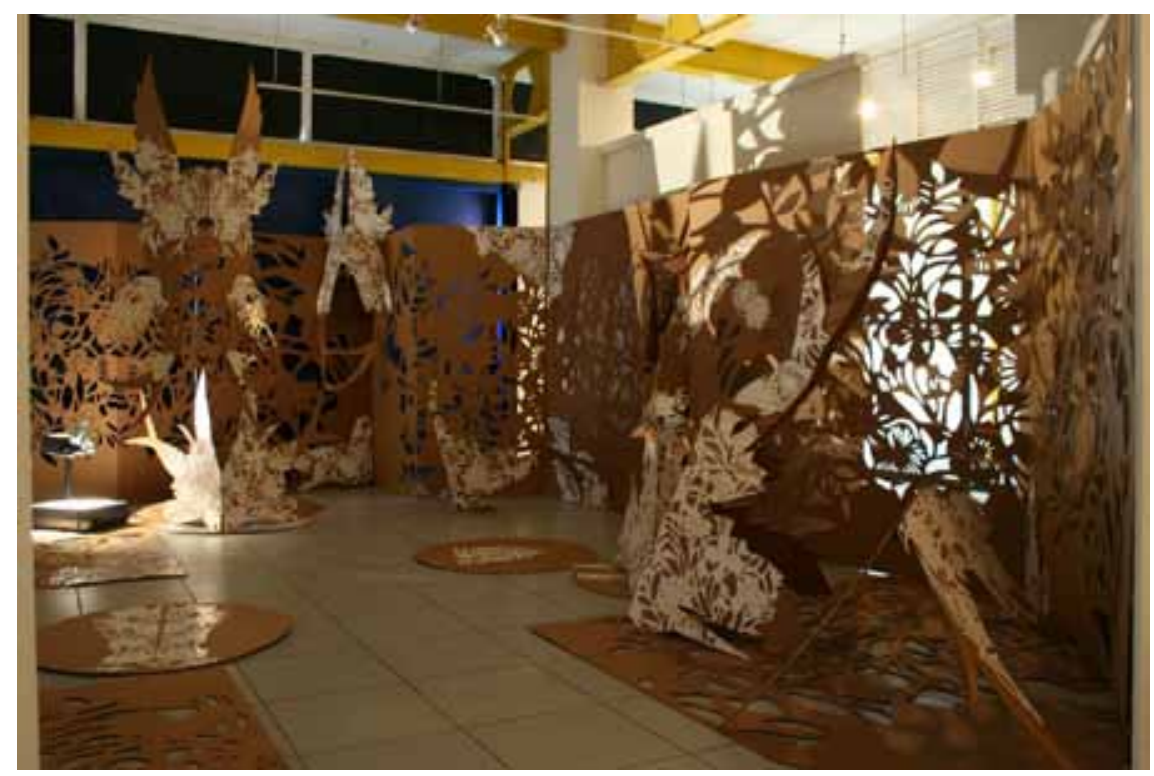

Figura 4: Marlon Griffith, Symbiosis, Cage Gallery, Edna Manley College, Kingston, Jamaica, 2007, curadoria de Veerle Poupeye

Foto: Cortesia do artista.

the Shadow: Trinidad in and out of Light (CCA7, Port of Spain, 2004, com curadoria desta autora), Griffith se apropriou de técnicas usadas na criação de moldes de fantasias de carnaval para criar impressões em plástico transparente de personagens carnavalescos projetados como sombras sobre as paredes da galeria. Com isso, ele afirmou que estava tentando evocar as emoções do Jouvé, o ritual de purificação noturno do domingo de carnaval, como fez Kathryn Chan que também contribuiu com a instalação inspirada no mas' que fazia parte da exposição. Em muitas outras instâncias, com Symbiosis (Cage Gallery, Edna Manley College, Kingston, Jamaica, 2007, curadoria de Veerle Poupeye) (Figura 4) e Trapped in a Memory (in Mas': From Process to Procession, BRIC's Rotunda Gallery, Brooklyn, Nova York, 2007, curadoria desta autora) Griffith criou ambientações orgânicas com a técnica de corte que se tornou sua marca registrada, usando a luz para refletir motivos móveis e, com isso, fazendo com que a sombra fragmentasse a imagem mesmo que ela se incorporasse à obra e se tornasse uma lembrança da qualidade transitória e efêmera do mas'. Quando incorpora manequins, na Mino Paper Art Village (2005) e em South-South: Interruptions and Encounters (Barnicke Gallery, University of Toronto, 2009, curadoria de Tejpal Ajji e Jon Sonske) Griffith desenha seu trabalho especificamente para o espaço da galeria em lugar de usar criações passadas como objetos. Quando usa criações passadas ele as coloca suspensas e não em manequins, em outra tentativa de respeitar a irrevogabilidade das dimensões espaçotemporais. (Figura 5)

Já foi sugerido que o espaço, e não a obra de arte, é o material do curador e seu instrumento a exposição (CHAN, 2011, p. 28-37). Quando o espaço é a rua, a obra de arte 
se torna obra de rua (roadwork), e a exposição, uma procissão, uma parada ou um desfile. É com essa compreensão do espaço que com Spring (5 de setembro de 2008) - o grupo processional que organizei para a VII Bienal de Gwangju, como curadora de projeto sob a direção artística de Okwui Enwezor - ofereci a Griffith a oportunidade para sua primeira "produção de rua em grade escala" (COZIER, 2009, p. 49) (Figura 6). Tendo escrito e falado extensivamente sobre Spring, ${ }^{13}$ vou dar voz a Cozier, esse comentador especialista em mas':

Spring propôs e implementou uma procissão de rua colaborativa e transcultural envolvendo artistas de Trinidad, Haiti, Brasil, França e Alemanha. Através dos processos desta colaboração, vários momentos - históricos e culturais - foram interligados (...). Tancons tentou mudar o diálogo do culturalismo antropológico para discussões comparativas com outros lugares (e momentos), onde ações de rua similares têm lugar. Como curadora do projeto ela também entrou no processo na qualidade de imaginadora/instigadora da "banda" em Gwangju. A linha entre curadoria e produção criativa tornou-se turva num espaço de exibição transitório, sem paredes e no domínio público. Utilizando o impulso do carnaval, Tancons está advogando outro caminho ou outra maneira de curadoria (COZIER, 2009, p. 50)

Inicialmente, compreendi meu papel como organizadora de Spring e de A Walk Into the Night (2 de maio de 2009) para Cape 09, a segunda bienal de Cape Town, de forma não diferente da que trabalhei em outros projetos curatoriais, tendo começado a pensar na ideia da procissão como formato curatorial ao menos desde Mas': From Pro-

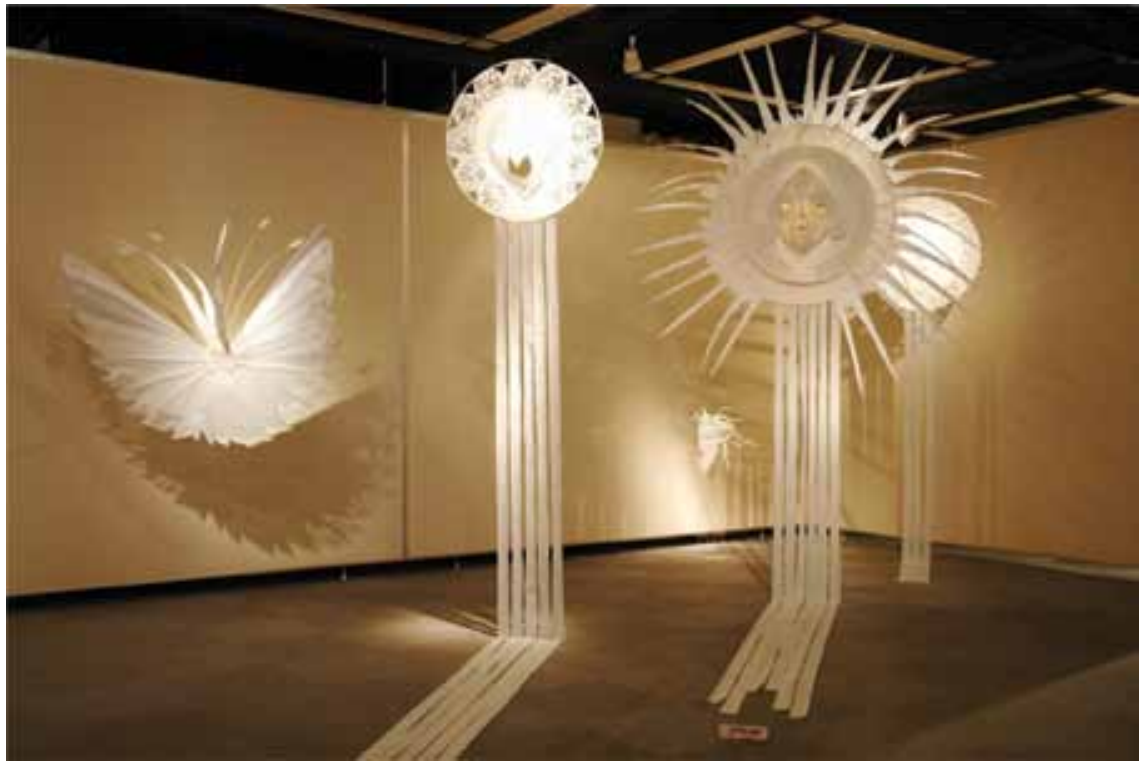

Figura 5: Marlon Griffith, exibição de artista residente, Mino Paper Art Village, Mino, Japan, 2005

Foto: Cortesia do artista.

TANCONS, Claire. Curadoria de carnaval? 


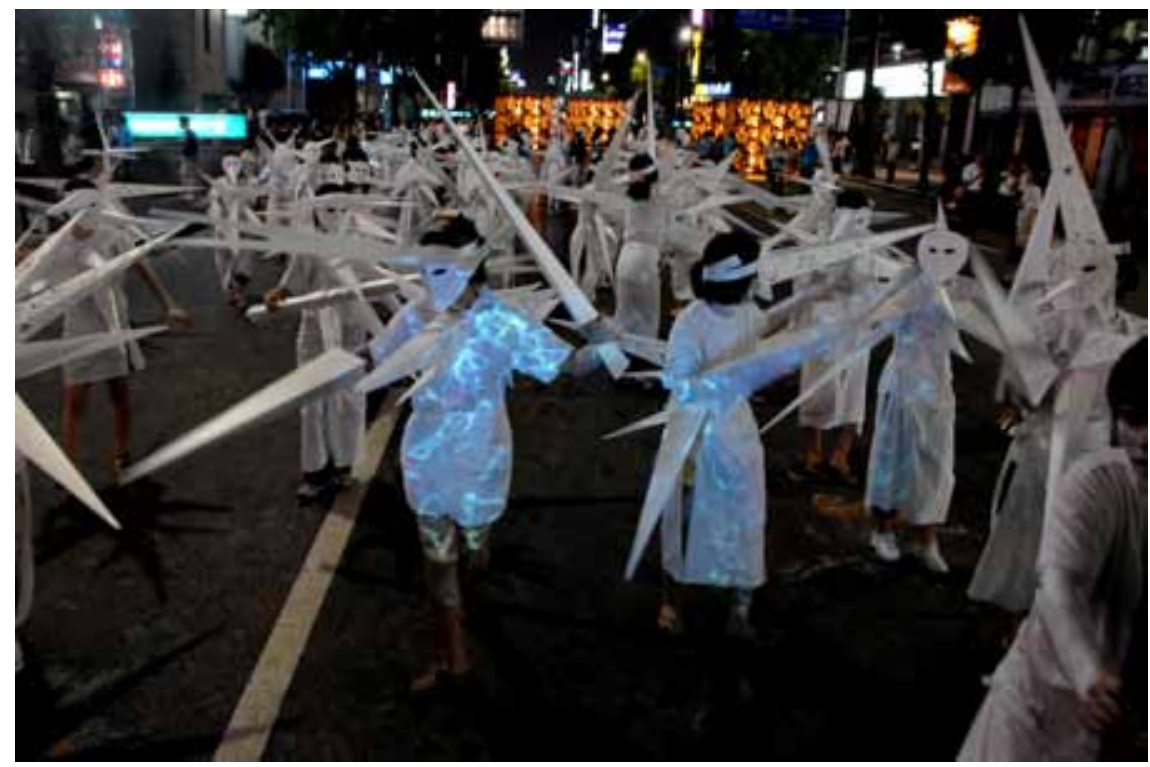

Figura 6: Marlon Griffith, Runaway/Reaction em Spring, Geumnamro, Gwangju, 5 de setembro de 2008, curadoria de Claire Tancons, VII Bienal de Gwangju; Griffith foi um dos cinco artistas destacados na procissão. Ao fundo vê-se a obra Le Banquet, de Mario Benjamin; outros artistas participantes: Jarbas Lopes, Karyn Oliver e MAP Office (Laurent Gutierrez e Valerie Portefaix)

Foto: Akiko Ota. Cortesia do artista.

cess to Procession, que era acompanhada por procissão, se não desde Lighting The Shadow: Trinidad in and out of light. Griffith, o principal artista em A Walk Into the Night, continuou organizando sua própria procissão Stuffed Swan (2010), como parte do Junkanoo, em Nassau. Tendo crescido em Guadalupe eu participei do vidé em Pointe-à-Pitre em minha infância e adolescência. Durante viagens de pesquisa, participei do Jouvé em Port-of-Spain algumas vezes desde 2005, corri no Junkanoo em Nassau em 2008, com a colega historiadora da arte e curadora Krista Thompson, andei para baixo e para cima no trio elétrico de Arto Lindsay na Bahia e desfilei com Jarbas Lopes na Mangueira, no sambódromo do Rio de Janeiro, em 2009. Pesquisei práticas artísticas e observei o meio cultural a partir do qual elas se desenvolveram e parti para criar uma metodologia que se adaptasse a produzir trabalhos fora de seu contexto original de criação. Fui apoiada nessa busca por contínuas conversações com Gulick, o que foi possível graças a Anthony "Sam" Mollineau, um dos últimos recrutas da Callaloo Company, além de participante do workshop e gerente de desfile de Spring. Para meus dois projetos de procissão, comecei por organizar o que pode ser entendido como um mascamp, barracão ou shack, que eram workshops durante os quais artistas criariam trabalhos com assistentes. ${ }^{14}$ Passei então a organizar curatorialmente uma procissão, uma parada, um desfile, levando em conta o espaço não limitado por paredes, pesquisando o passado dos tempos imemoriais de 
festivais populares e sintonizando com um futuro de movimentos de massa globalizados.

Enwezor, que em 2008 me falou que, sendo nigeriano, ele sabia o que significava uma mascarada, de onde eu estava vindo e para onde eu estava indo, foi o primeiro a se referir a mim como produtora, em meu papel de organizadora de uma procissão. Em conferência recente, o historiador da arte brasileiro Roberto Conduru respondeu a minha apresentação de Spring dizendo que o carnaval já tem seus curadores, os carnavalescos. Por sua vez, a curadora e historiadora da arquitetura brasileira Paola Berenstein Jacques, aventurou-se a dizer que eu era uma carnavalesca. ${ }^{15} \mathrm{Em}$ Trinidad o termo seria maswoman. Enquanto o carnaval de Trinidad pode ser considerado não só gerador de nova língua franca artística, sob a forma do mas', mas também reinventor de antigo modelo performático exibicionístico especialmente adaptado à cultura cerimonial pública das ruas do Caribe, a procissão ou parada, o carnaval do Rio criou seu próprio estádio-museu para o carnaval, o sambódromo.
14. "Mascamp", "barracão" e "shack" são nomes das unidades básicas de produção similares a workshop nos carnavais de Trinidad e Rio de Janeiro e no Junkanoo das Bahamas, respectivamente.

15. Por ocasião da leitura de meu texto Carnaval do Sublime no painel Contemporary Art in the South Atlantic? Images and Strategies na conferência Terceira Metade/Third Half no Museu de Arte Moderna do Rio de Janeiro, março 29 e 31 de março de 2011.

A verdade é que eu nunca tive a intenção de ser produtora, carnavalesca ou maswoman, e a proposição de "curadoria de carnaval" continua sendo arriscada. Entretanto, porque carnavalescos no Brasil, masmen em Trinidad, junkanoo-makers nas Bahamas e crop-over designers em Barbados continuam a fazer ousadas intervenções artísticas contemporâneas, e artistas e público através das Américas criam e participam do carnaval, ele continua necessário. Visto que a arte caribenha contemporânea integra com maior presença o mundo da arte global contemporâneo e sua tradição de performance é reconhecida com sendo central a essa integração, ela se torna urgente.

\section{REFERÊNCIAS BIBLIOGRÁFICAS}

BHABHA, Homi K. Unsatisfied: notes on vernacular cosmopolitanism, In: GARCIA-MORENO, Laura and PFEIFFER, Peter C. (eds.). Text and nation: cross-disciplinary essays on cultural and national identities. Columbia: Camden House, 1996, p. 191-207.

CAMNITZER, Luis, The Keeper of the Lens. In: Looking at the Spirits: Peter Minshall's Carnival Drawings. New York: The Drawing Center, 2005.

CHAN, Carson. Measures of an Exhibition. Fillip, Issue n.3, Spring 2011, pp 28-37.

COZIER, Christopher. Mancrab. Manuscrito, s/d. . Manuscrito de palestra proferida em 1998 (b).

. Shifting Signs and Transitional Moments. In: South-South: Interruptions and Encounters. Toronto: The Justina M. Barnicke Gallery, 2009.

. Trinidad: Questions about Contemporary Histories, In: Caribe Insular. Exclusión, Fragmentación y Paraíso. Madrid/Junta de Extremadura: Casa de América/MEIAC, Museo Extremeño y Iberoamericano de Arte Contemporáneo, 1998(a), p. 348-349.

DANERI, Anna. The Carnival of Art. Mousse, December-January 2009, 81-83. 
DUNLAP, William. The Island of Reflected Images. Two-month festival brought out the best of Havana's contemporary art scene. The Washington Post, Sunday, February 18, 2001, p. G4.

GULICK, Todd. Notas explicativas ao manuscrito de William Dunlap, The Peter Minshall Archives, Callaloo Company, Chaguaramas, Trinidad and Tobago, W. I, s/d.

HILL, Errol. The Trinidad Carnival: mandate for a National Theatre. Austin: University of Texas Press, 1972.

. Trinidad Carnival: history and meaning. In: Caribbean visions: contemporary painting and sculpture. Alexandria: Art Services International, 1995, 43-47.

LAUGHLIN, Nicholas, That is mas. In: BACKER, Yona and NEWMAN-SCOTT, Kristina (eds.). Rockstone and Bootheel, Contemporary West Indian Art, Hartford, Ct: Real Art Ways, 2010, p. 22-27.

MCKEE, Jesse. Mythographies, Archeologies, Circuitries. Other Ways of Curating. BorderCrossings, v. 29, n. 2 (\#114), February 2010, p. 66-67.

MERCER, Kobena (ed.). Cosmopolitan Modernism. Boston/London: MIT Press/inIVA, 2008.

MINSHALL, Peter. Carnival and its place in Caribbean culture and art. In: Caribbean visions: contemporary painting and sculpture. Alexandria: Art Services International, 1995, p. 49-57.

NUNLEY, John and BETTELHEIM, Judith (eds.). Caribbean Festival Arts. Seattle/St. Louis: the University of Washington Press/St Louis Art Museum, 1988.

PAUL, Annie. Visualizing Art in the Caribbean. MOSAKA, Tumelo (ed.). Infinite island: contemporary Caribbean art. Brooklyn/London: Brooklyn Museum/Philip Wilson Publishers, 2007.

POUPEYE, Veerle. Caribbean Art. New York: Thames \& Hudson, 1998.

RIGGIO, Milla (ed.). Carnival: Culture in Action - The Trinidad Experience. New York/London: Routledge, 2004.

SCHNEIDER, Anna. Architectures of Spectacle. Facets of the exhibition boom in South Korea and China in the context of the strategy of globalism. Springerin, Issue 1/09, January 2009 (www.springerin.at/dyn/heft.php?id=58\&pos=1\&textid=2167\&lang=en).

TANCONS, Claire. Carnival as Counter-Curatorial Intervention. In: Viz.Inter-Arts. UC Santa Cruz, 2011 (no prelo).

Spring. In: The $7^{\text {th }}$ Gwangju Biennale. Annual Report: A Year in Exhibitions, Gwangju: Gwangju Biennale Foundation, 2008, p. 334-363

. The Greatest Free Show on Earth. Carnival from Trinidad to Brazil, Cape Town to New Orleans. In: CAMERON, Dan (ed.). Prospect.1 New Orleans, New York: PICTUREBOX, 2008.

TANCONS, Claire and MCKEE, Jesse. On Carnival and Contractual Curating. Fillip, Issue n.13, Spring 2011, p. 74-79.

Claire Tancons é curadora, escritora e pesquisadora baseada em Nova Orleans com trabalho focado em carnaval, formas de arte processionais e movimentos populares. 